\title{
PASAR KREATIF KULINER
}

\author{
Ashila Ashara Amalia1), Suwandi Supatra ${ }^{2)}$ \\ 1)Program Studi S1 Arsitektur, Fakultas Teknik, Universitas Tarumanagara, asharashila@gmail.com \\ 2)Program Studi S1 Arsitektur, Fakultas Teknik, Universitas Tarumanagara, ybhan50@gmail.com
}

\begin{abstract}
Abstrak
Kehidupan kota dikenal dengan kehidupan arus padat 24/7. Kegiatan monoton yang dilakukan warga kota membuat masyarakat merasa bosan dan jenuh. Dibutuhkan satu tempat untuk mereka melepas penat sebentar, dan disitulah dibutuhkan third place. Studi menyebutkan bahwa kehidupan kota mempunyai masalah dengan kesehatan fisik dan mental warga kota. Hiburan sederhana, seperti live music atau sekedar makan dan kumpul bersama menjadi sasaran bagi warga kota dalam menghilangkan penat sejenak. Proyek dengan judul $C$ (reative)ulinary Market adalah proyek rancangan bertemakan third place bagi masyarakat kota. Berlokasi di Palmerah, dengan 3 isu yaitu aktivitas padat pagi hingga malam yang menyebabkan pola gaya hidup tidak sehat, tidak ada hubungan erat antar masyarakat, dan tidak ada ruang bermain bagi anak-anak. Menggunakan metode perancangan dis-programming dan behavioural architecture, dimana mengkombinasi program dengan sifat berbeda dan juga meneliti dan mengkaji perilaku masyarakat sekitar tapak. Konsep desain bertajuk pada broad food system yang berpengaruh pada denah dan sirkulasi proyek. Program yang disediakan terdapat 2, kuliner kreatif (creative culinary) dimana terdapat market \& food space guna untuk bersosialisasi dan berkumpul bersama sambil makan dan ada cooking class, ruang aktif-sosial (active and social space) terdapat playground dan roof garden serta taman di tapak. Kedua program penting di atas bertujuan untuk memberikan tempat bersosialisasi sekaligus memberikan edukasi akan pentingnya hidup sehat. Selain itu, makanan juga menyatukan antar sesama.
\end{abstract}

\section{Kata Kunci: Aktif; Kuliner Kreatif; Kota; Makanan; Sehat}

\begin{abstract}
City life itself known for the busy 24/7 with non-stop busy activities. Monotous activities carried out by city residents makes them frustrated and bored. A need for a place to let them rest for a bit, and that's where third place is needed. Study stated that city life has problems within the physical and mental health of the residents itself. A simple entertainment such as live music or gathering over food has become their go to rest. C(reative) ulinary Market is a project with third place as the theme for the city residents. Located in Palmerah, within 3 issues detected which area morning to night activities that cause unhealthy lifestyle patterns, no bonding between communities, and no play space for children. Using the design method of dis-programming and behavioural architecture, which comebines program within different properties and examines surrounding people activities. Design concept based on broad food system in which influences for the layout and circulation. 2 program provided, creative culinary in where there's market and food space for socializing and gather over food, and there's also cooking class. Active and social space, there's playground, roof garden, and park within the site. Two important program above aim to provide a place to socialize while providing education on the importance of healthy living. In addition, food brings people together.
\end{abstract}

Key words: Active; City; Creative Culinary; Food; Health 


\section{PENDAHULUAN}

Kehidupan kota dikenal dengan arus kehidupan yang cepat dan padat. Kegiatan monoton yang dilakukan warga kota, dimana pada umumnya adalah bekerja atau sekolah lalu pulang kerumah, membuat warga kota merasa jenuh. Studi dari National Institutes of Health menyebutkan bahwa keramaian dan hiruk pikuk kehidupan kota dapat merusak kesehatan fisik dan mental secara perlahan, seperti gangguan kecemasan dan masalah emosi. Pencarian hiburan menjadi pelarian bagi mereka, seperti makan di luar atau sekedar berjalan-jalan. Suasana dan ruang yang berbeda menjadi tujuan warga kota suka berada di luar rumah.

Diperlukan keseimbangan antar kehidupan bersosialisasi dengan kehidupan pekerjaan, karena kenyataannya bahwa manusia adalah makhluk sosial. Tapak berlokasikan di Palmerah, dimana permasalahan di kawasan adalah kurangnya kegiatan padat pagi hingga malam yang berakibat kurangnya aktivitas social antar warga, serta tidak ada tempat bermain bagi anak-anak. Disini keberadaan third place menjadi peran penting bagi kehidupan bermasyarakat.

Third place muncul sebagai ruang perantara antara first place (home) dan second place (tempat kerja), dimana berperan sebagai tempat menghabiskan waktu dan melepaskan penat, bertukar pikiran/ide, berinteraksi dan membangun komunitas. Third place juga sebagai satu ruang dimana kita lepas sejenak dari kehidupan kota yang hectic dan padat, dari rumah ataupun tempat kerja kita, menjadi tempat untuk bersantai. Bertujuan untuk memberikan ruang/tempat bagi masyarakat Palmerah untuk bersantai dan bersosialisasi, menikmati makan di luar rumah ataupun tempat kerja.

\section{KAJIAN LITERATUR}

\section{Open Architecture}

Space adalah suatu ruang, yang jika di dalam ruang itu terjadi pergerakan dan ada aktivitas tertentu maka space akan menjadi place, hal ini yang membedakan space dan place [Yi Fu, 1977]. Hal ini dipelajari oleh Moretti menggunakan metode pencarian dari museum dan isi dalamnya. Fokus utama dimana momen pergerakan subjek terganggu dan proses dari semua ini merubah space menjadi place [Structures and Sequences of Spaces, 1952]. Open Architecture adalah konsep yang menekankan keterbukaan (openness), berspesifikasi atau bersifat publik dan bisa menerima berbagai program di dalamnya. Open Architecture for Third Place merupakan konsep yang diterapkan di dalam third place itu sendiri, dimana third place dirancang mempunyai program utama yang di dukung oleh beberapa program pendukung lainnya, yang berkontradiksi. Berkontradiksi disini merupakan bentuk keterbukaan dari desain arsitektur tersebut dimana pergerakan manusia bisa merubah space menjadi place.

\section{Third Place}

Third place muncul dengan adanya first place dan second place. Third place adalah istilah yang dikemukakan oleh sosiologis kota, Ray Oldenburg dalam bukunya The Great Good Place, 1991. Third place adalah tempat dimana orang menghabiskan waktu antara first place (tempat tinggal) dan second place (tempat kerja). Di tempat ini lah dimana orang-orang bisa bertukar pikiran dan informasi, berinteraksi, menikmati waktu dan bersantai, dan juga membangun satu komunitas. Third place menjadi wadah bagi masyarakat dalam berkehidupan social.

\section{Kota}


Kota adalah suatu permukiman yang dirumuskan berdasarkan suatu fungsi yang menciptakan ruang-ruang efektif melalui pengorganisasian ruang dan hirarki tertentu [Amos Rapoport,1967]. Di dalam kota juga terdapat masyarakat dengan beragam aktivitas yang diwadahi oleh kota, tetapi beberapa aktivitas masyarakat ada yang tidak diwadahi oleh kota. Aktivitas masyarakat kota membentuk satu gaya hidup yang diterapkan masing-masing individu.

\section{Gaya Hidup}

Gaya hidup adalah pola tingkah laku sehari-hari segolongan manusia dalam masyarakat [KBBI, 2008]. Definisi lain adalah gaya hidup sebagai model kehidupan yang di identifikasikan dari bagaimana seseorang menghabiskan waktu mereka (activities), apa yang menurut mereka penting di lingkungan mereka (interest), dan apa yang mereka pikirkan tentang diri mereka sendiri dan tentang dunia di sekitar mereka (opinions) [Assael, 1992]. Bagaimana seseorang menjalani hidupnya juga tergantung faktor orang-orang di sekitar mereka.

\section{Makanan}

Menurut WHO [World Health Organization], makanan adalah semua substansi yang dibutuhkan oleh tubuh tidak termasuk air, obat-obatan dan substansi lain yang digunakan dalam pengobatan. Makanan sebagai sumber energi, zat pembangun dan juga zat pengatur untuk tubuh. Makanan dibutuhkan manusia agar badan tetap sehat, tumbuh dan berkembang secara baik. Tiga macam makanan yaitu makanan pokok, lauk pauk, dan sayur dan buah.

\section{Hubungan antar Kota, Gaya Hidup, dan Makanan}

Kota bersifat acak, berarti kota memiliki gaya yang berbeda dengan aktivitas yang berbeda dengan manusia yang berbeda di dalamnya. Tiap kota memiliki ciri khas masing-masing dengan apa yang diterapkan di dalamnya, dimulai dari etika yang diterapkan. Aktivitas beragam warga kota menjadi salah satu faktor pembentukan gaya hidup masyarakat kota. Salah satu gaya hidup warga kota yaitu makan di luar. Pencarian hiburan untuk kabur sejenak dari kejenuhan kehidupan sehari-hari dan untuk menjernihkan pikiran. Mereka mencari suasana dan ruang yang baru juga mengutamakan kenyamanan dan keamanan. Penelitian Nielsen menunjukkan $11 \%$ masyarakat Indonesia gemar bersantap diluar paling tidak 1x sehari. Angka tersebut termasuk tinggi karena secara global rata-rata hanya $9 \%$. Hal ini juga berhubungan dengan tren dan kebudayaan yang diterapkan oleh masyarakat Indonesia yang memang gemar berkumpul bersama keluarga dan teman.

\section{METODE}

Metode perancangan menggunakan metode dis-programming [Tscumi, 2005] yang mengkombinasikan dua program yang sifat dan konfigurasi spasialnya berbeda tanpa melihat kecocokan. Selain itu juga menerapkan metode behavioural architecture, yang dimana menciptakan ruang dan suasana yang sesuai dengan perilaku manusia, lingkungan dan budaya masyarakat.

Metode pengumpulan data dari studi literatur teori-teori yang bersangkutan dengan tema dan proyek, studi preseden dari yang cocok dan sejenis dengan proyek yang akan dibangun dan survey lapangan untuk langsung mengetahui kondisi lapangan.

\section{DISKUSI DAN HASIL}


Pasar Kreatif-Kuliner atau C(reative)ulinary Market ini berlokasi di Palmerah, Jakarta Barat, tepatnya di Jl. Palmerah Barat. Dibangun diatas tanah dengan luas $\pm 3085 \mathrm{~m}^{2}$. Kawasan Palmerah termasuk kawasan yang cukup padat dengan perumahan dan juga perkantoran. Dalam jarak 500m tapak berada dekat dengan perkantoran, pasar, stasiun KRL, perumahan warga dan juga sekolah. Dengan jarak 500m tapak dekat dengan stasiun KRL yang langsung tersambungkan dengan halte Transjakarta, memudahkan akses untuk ke tapak.

Terdapat dua program utama yaitu kuliner-kreatif (creative culinary) dan ruang aktif-sosial (active social space).
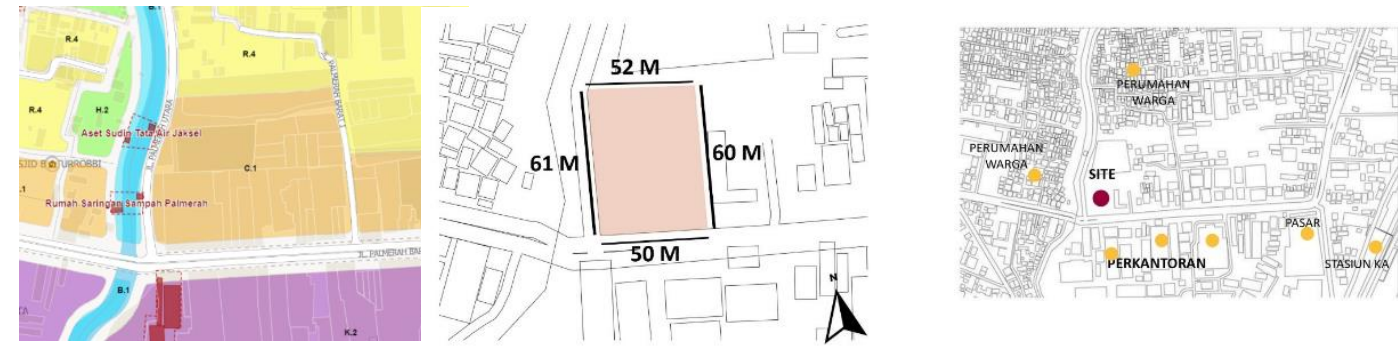

Gambar 1. Zonasi Tapak dan Sekitarnya

Sumber: JakartaSatu, Dokumen Pribadi, 2020

Tapak berada di kawasan zonasi peruntukkan campuran dan kondisi eksisting adalah tanah kosong yang dahulunya bekas pabrik makanan. Berdasarkan survey lapangan dan menganalisa data-data yang didapatkan, tapak termasuk dalam lokasi strategis dan juga berada ditengah antar first place dan second place masyarakat. Tapak tepat berada di pertigaan jalan yang dimana pada beberapa waktu, seperti pagi atau sore, terhitung ramai dikarenakan beberapa aktivitas yang dilakukan oleh warga. Tepat di sebelah kiri tapak terdapat pos yang digunakan sebagai tempat berkumpul warga sekitar, akan tetapi mereka merasa membutuhkan satu tempat untuk berkumpul dan juga bersosialisasi.

Diangkat 3 isu dari tapak yaitu aktivitas padat yang menyebabkan gaya hidup tidak sehat, tidak ada keeratan antar masyarakat, dan tidak ada tempat bermain bagi anak-anak. Diajukan 3 program yaitu adanya pasar (market), kelas aktivitas (activity class) guna mengeratkan hubungan masyarakat, dan adanya tempat bermain karena di sekitar tapak tidak terdapat taman ataupun RPTRA.

Program-program di atas bertujuan untuk mengedukasi, membentuk hubungan sosial antar masyarakat, dan juga menambah penghijauan di dalam dan luar tapak. Fasilitas utama yaitu untuk creative culinary (60\%) dimana terdapat market \& food space, activity class (30\%) dimana terdapat playground, farming space dan roof garden. Sisa $10 \%$ untuk service dan lainnya.

Dilakukan beberapa analisis, dicapai hasil rancangan untuk proyek tersebut:

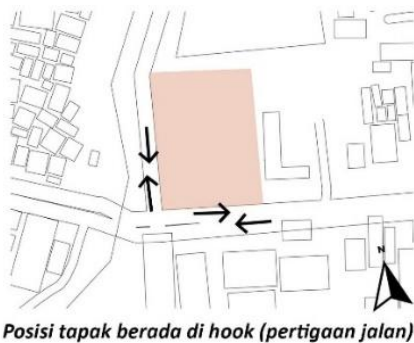

Posisi tapak berada di hook (pertigaan jalan)

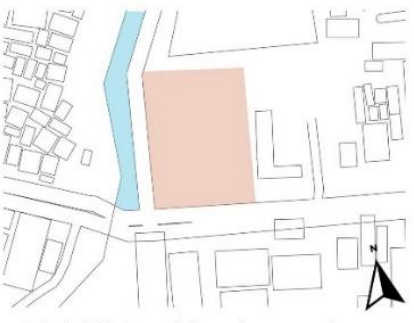

Sebelah kiri tapak bersebrangan dengan kali Grogol

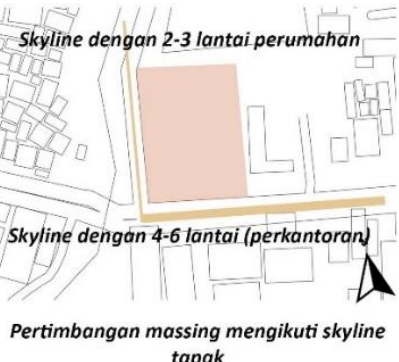

tapak 


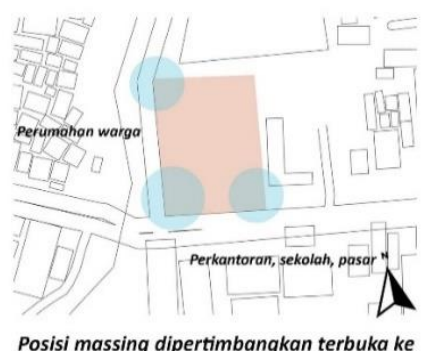

2 arah

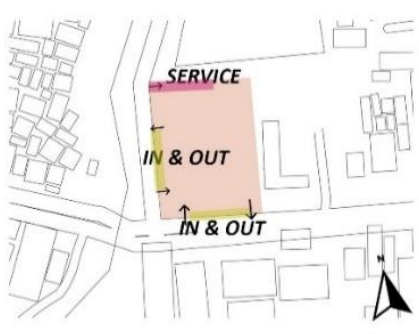

Pertimbangan akses masuk ke tapak dan loading dock

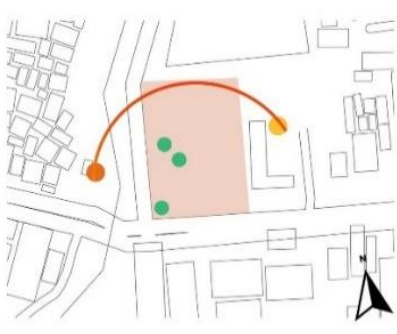

Menggunakan vegetasi dan permainan massing sebagai sun shade

Gambar 2. Analisis Tapak

Sumber: Dokumen Pribadi, 2020

Tapak berada tepat di pertigaan, sehingga memungkinkan untuk arah masuk dari 2 arah yaitu dari Jl. Palmerah Barat dan dari Jl. Palmerah I. Selain itu, dipertimbangkan juga arah massing yang terbuka untuk 2 arah. Tinggi bangunan disamakan pula dengan skyline kawasan, dimana terdapat rumah dengan 2-3 lantai dan perkantoran dengan 4-6 lantai. Vegetasi pada tapak juga di maksimalkan.

Dilakukan analisis tapak yang berpengaruh ke dalam pembentukan massing dan nantinya ke dalam penempatan ruang. Gubahan massa terbuka di bagian kiri dan depan tapak dikarenakan berhadapan langsung dengan jalan, tapak berada di pertigaan jalan. Sedangkan area tengah gubahan diperuntukkan sebagai active $\&$ social space. Selain itu, menerapkan konsep Broad Food System yaitu production $\rightarrow$ distribution $\rightarrow$ preparation $\rightarrow$ consumption $\rightarrow$ waste dan menerapkannya ke dalam denah yang juga mengatur sirkulasi manusia dalam bangunan.

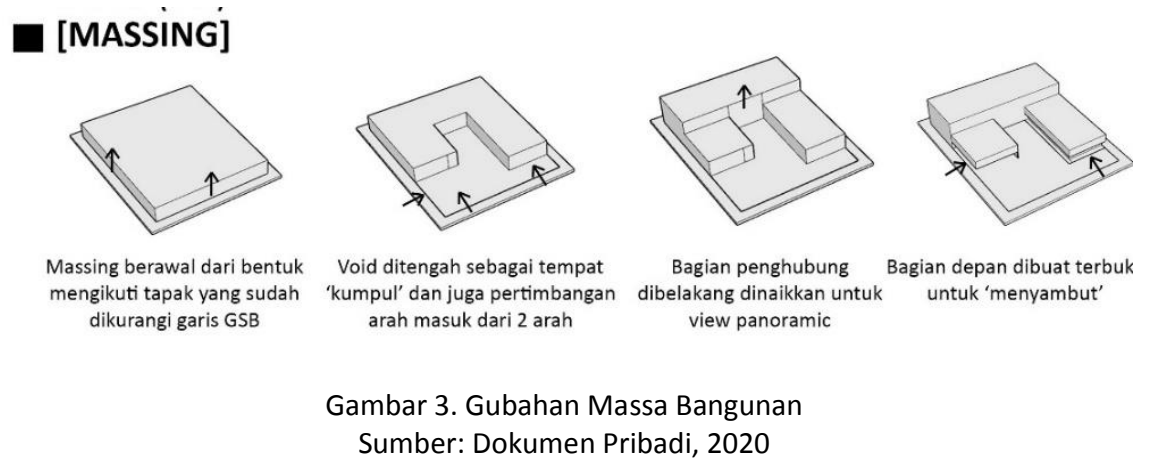




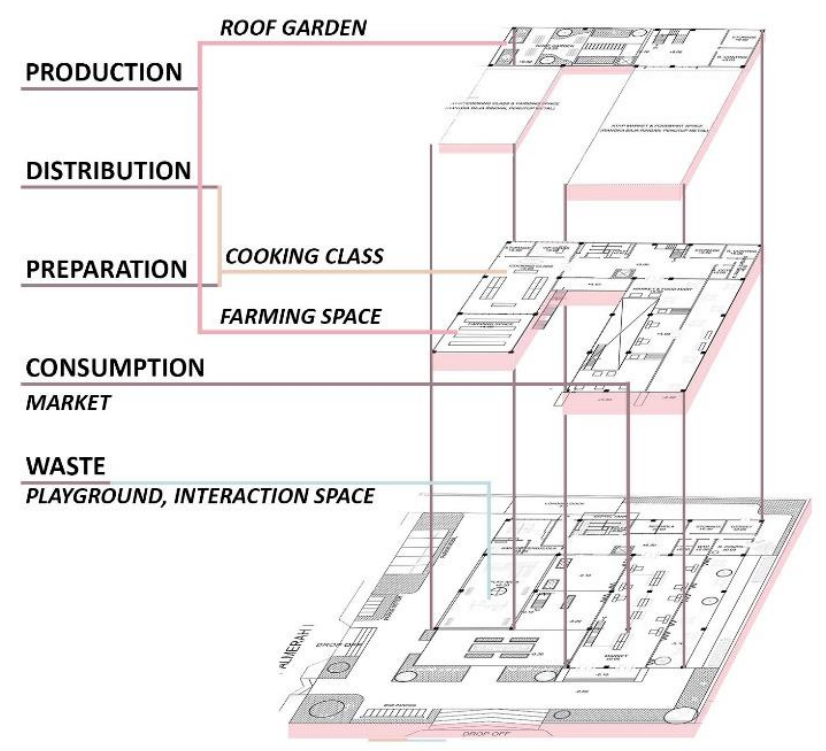

Gambar 4. Konsep masuk Denah

Sumber: Dokumen Pribadi, 2020

Perumpamaan dari konsep broad food system dimana roof garden dan farming space diumpamakan sebagai tempat 'produksi', yang kemudian di distribusikan dan di siapkan di kelas memasak, yang langsung siap untuk di konsumsi di market. Setelah makan, ada baiknya untuk beraktivitas sehingga di sediakan play area dan interactive space guna bersosialisasi dan beraktivitas.

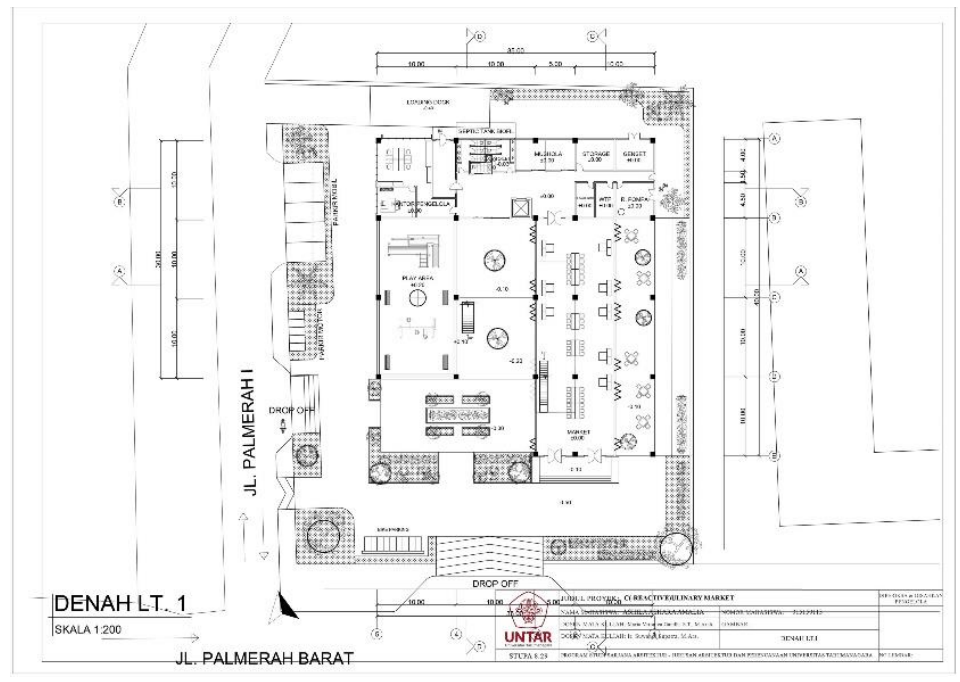

Gambar 5. Denah Lt. 1

Sumber: Dokumen Pribadi, 2020 


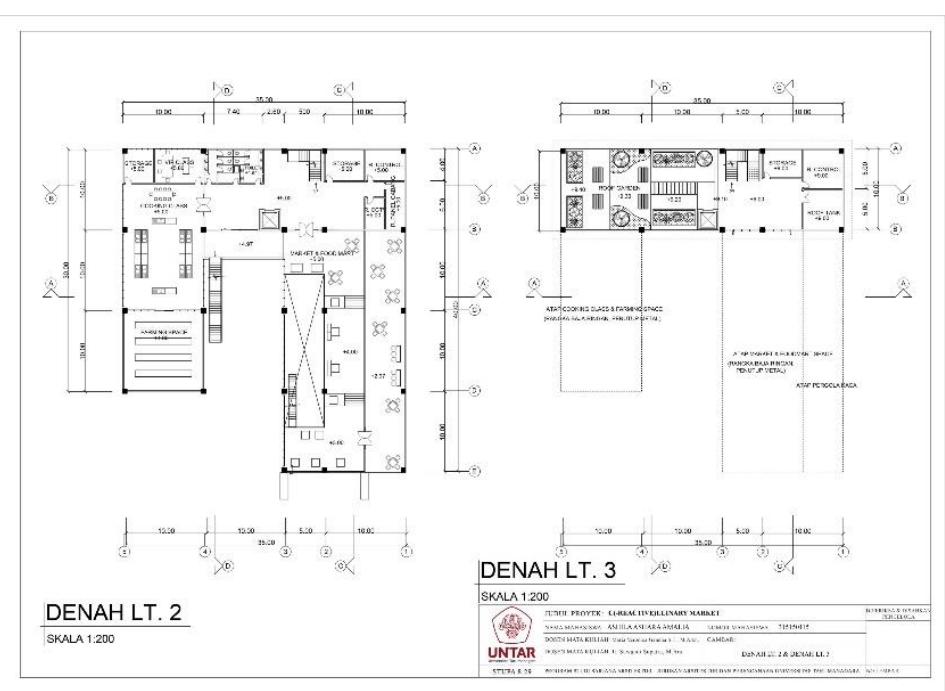

Gambar 6. Denah Lt. 2 dan Lt. 3

Sumber: Dokumen Pribadi, 2020

Untuk bagian Creative Culinary (Kuliner Kreatif), terdapat market atau pasar terbuka dan luas layaknya di luar negeri, dimana di satu ruang terdapat pedagang dan beberapa meja untuk menyantap makanan. Disajikan pula makanan sehat karena terdapat isu aktivitas warga kota yang padat mengakibatkan gaya hidup yang tidak sehat. Kelas aktivitas yaitu kelas memasak, yang diperuntukkan bagi siapa saja dan bertujuan untuk membangun hubungan aktif antar sesama. Play area atau taman bermain untuk anak-anak terhubung langsung dengan market dan berada di ruang terbuka. Farming Space dan Roof Garden tempat untuk bersosialisasi dan juga belajar tentang kehidupan tumbuhan. Selain karena konsep yang diterapkan, taman diletakkan di lantai atas dengan tujuan pemandangan panorama ke sekitar kawasan.

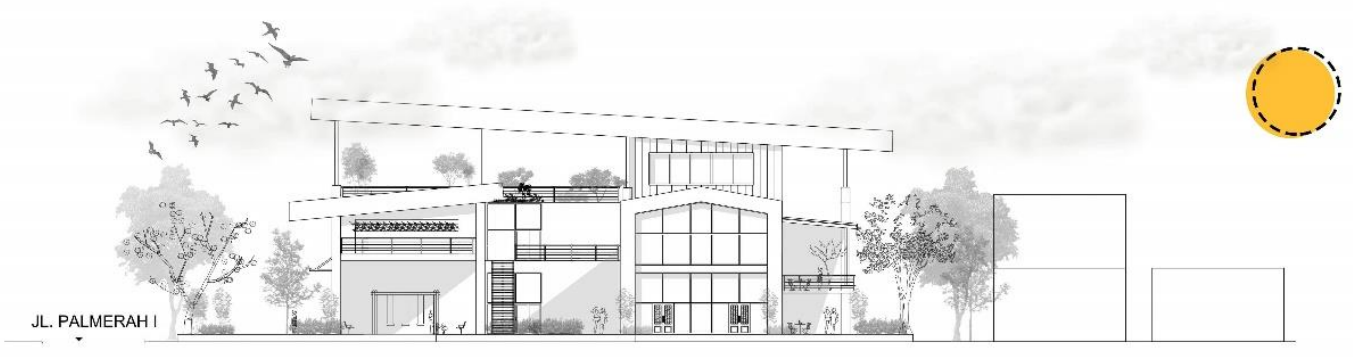

Gambar 7. Tampak Depan Bangunan Sumber: Dokumen Pribadi, 2020

Tampak bangunan disesuaikan dengan kontekstual sekitar, dimana bagian atap disesuaikan dengan perumahan warga sekitar yang banyak menggunakan atap pelana dan juga pemakaian kaca di bangunan ruko dan kantor sekitar. Selain itu pemaksimalan cahaya yang masuk ke dalam bangunan juga diperhatikan agar tidak kurang dan berlebihan dan juga mengurangi penggunaan pencahayaan buatan pada siang hari (lampu listrik). Pada bagian market, tampak adalah kaca semua dan dimajukan sedikit menggunakan kolom agar menutup sedikit cahaya matahari yang masuk untuk tidak berlebihan. Bagian outdoor market lantai 2 diberikan tanaman gantung guna mengurangi cahaya matahari berlebihan dari arah timur, selain itu juga untuk mempercantik interior bagian teras dari market. 


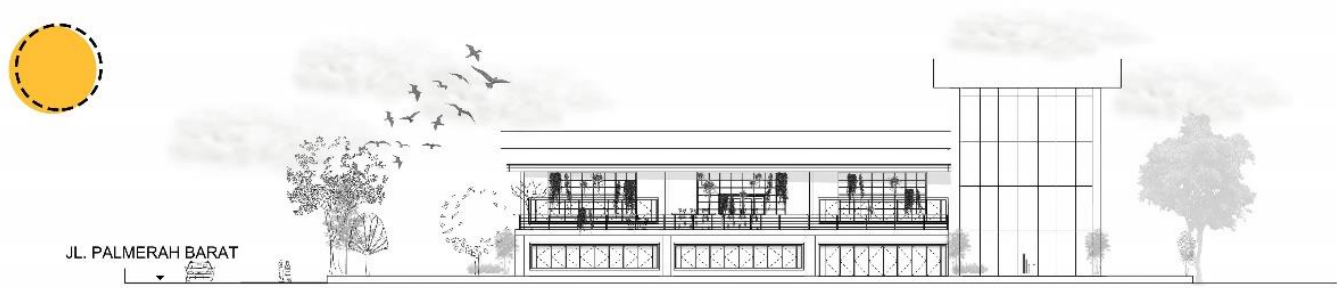

Gambar 8. Samping Kanan Bangunan Sumber: Dokumen Pribadi, 2020

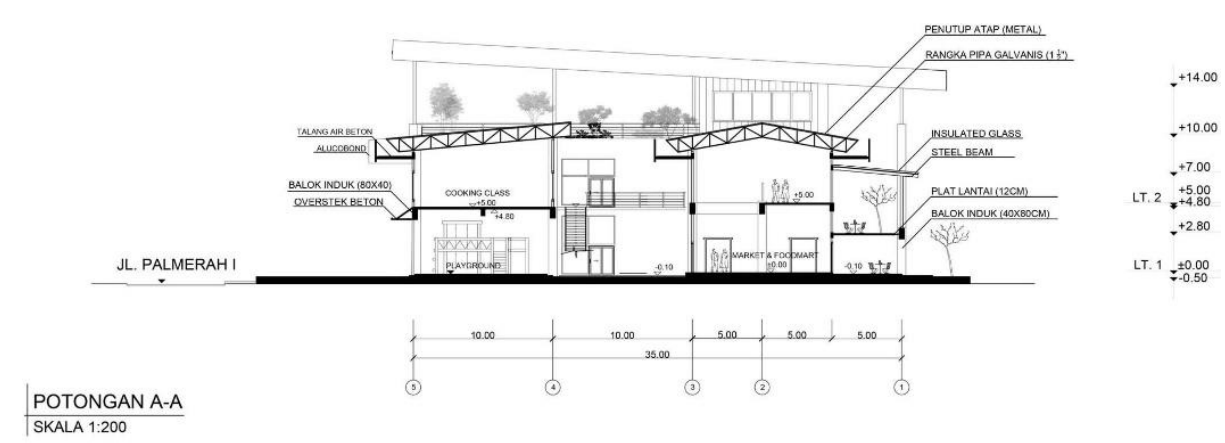

Gambar 9. Potongan A-A

Sumber: Dokumen Pribadi, 2020

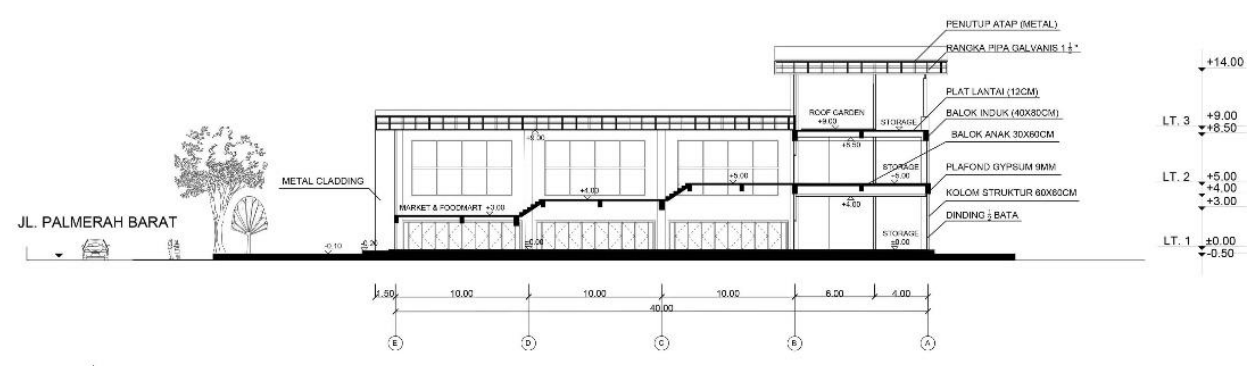

POTONGAN C-C

Gambar 10. Potongan B-B

Sumber: Dokumen Pribadi, 2020

Pada bagian market, bisa terlihat di potongan bahwa ada permainan lantai dimana tiap naik/turun 1 meter. Permainan peil lantai ini berguna dalam memaksimalkan ruang/area duduk dan santai bagi pengunjung. Void dari lantai 1 ke lantai 2 dibuat agar tidak terkesan sempit dan untuk memperluas. Selain itu, penggunaan kaca di sekeliling market juga untuk memaksimalkan cahaya masuk dan memberi kesan luas pada bangunan. 
Visual eksterior dan interior bangunan:
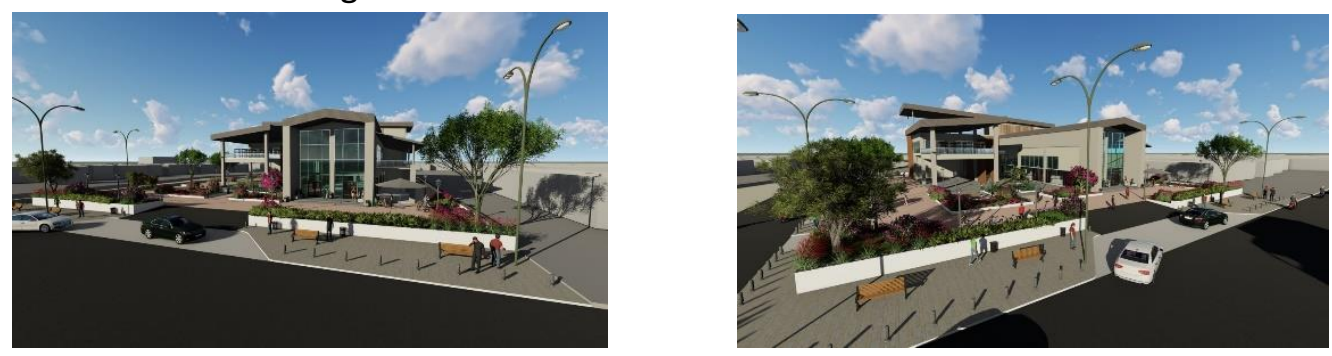

Gambar 11. Perspektif Eksterior Bangunan

Sumber: Dokumen Pribadi, 2020

Alur sirkulasi pengunjung juga diperhatikan dan dibuat semudah mungkin dalam pencapaian dari satu ruang ke ruang lainnya. Selain itu, diberikan vegetasi yang lumayan banyak juga karena mengingat tapak berada dekat dengan jalan yang padat pada beberapa waktu dan juga untuk meredam kebisingan dan asap dari kendaraan masuk ke tapak. Vegetasi juga di atur untuk memberikan kenyamanan bagi pengunjung apabila mereka menyantap makanan ataupun sekedar menikmati suasana. Penggunaan vegetasi di tapak memang di maksimalkan. Di tapak ini pula pengunjung dapat bersosialisasi dan berkumpul tanpa harus membayar.

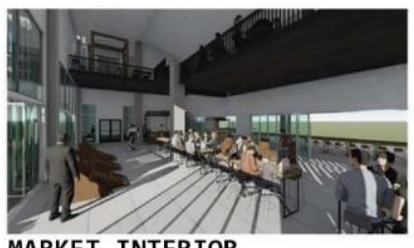
MARKET INTERIOR
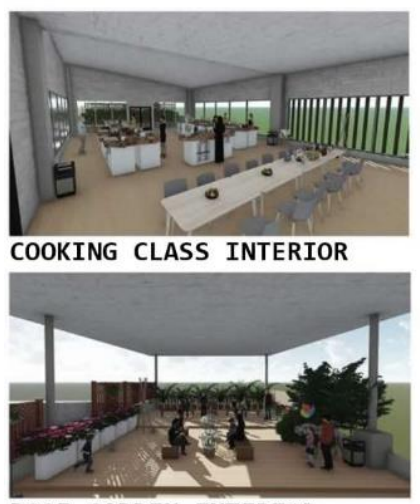

ROOF GARDEN INTERIOR

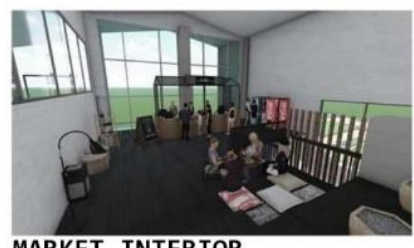

MARKET INTERIOR

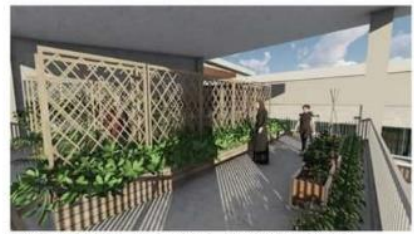

FARMING SPACE INTERIOR

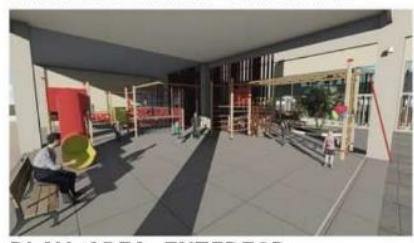

PLAY AREA INTERIOR

Gambar 12. Perspektif Interior Bangunan

Sumber: Dokumen Pribadi, 2020

\section{KESIMPULAN DAN SARAN}

Proyek Pasar Kreatif Kuliner bisa menjadi salah satu jawaban akan dibutuhkannya third place di tengah kota. Masyarakat membutuhkan satu ruang/tempat untuk melepas penat sejenak dari kegiatan monoton sehari-hari. Hal sederhana seperti makan diluar sering diterapkan oleh mereka. Dengan isu yang ada dan usulan program yang diterapkan, diharapkan dapat mengurangi isu yang ada dan juga membangun erat kebersamaan antar masyarakat. Pemerhatian terhadap masyarakat menjadi poin utama untuk menyusung keamanan dan kenyamanan bagi masyarakat untuk berkunjung. 
Untuk proyek third place tersendiri, perlu diperhatikan bagaimana kawasan mempunyai satu isu sehingga dibutuhkannya third place. Kawasan Palmerah mempunyai isu yang berkaitan dengan kehidupan sehari-hari dan juga berkaitan dengan gaya hidup yang diterapkan. Diperlukannya perhatian khusus terhadap bagaimana third place akan mewujudkan jawaban dari isu masyarakat yang ada. Selain itu, untuk bangunan tersendiri juga perlu diperhatikan alur dan sirkulasi pengunjung karena yang terpenting adalah kenyamanan dan keamanan pengunjung sekitar.

\section{REFERENSI}

Ching, F. D.K. (1996). Architecture: Form, Space and Order $2^{\text {nd }}$ Edition. Canada: John Wiley \& Sons Fraga, J. (2019). Here's How Living in a City Can Mess with Your Mental Health, dalam https://www.healthline.com/health/mental-health/living-in-a-city\#1 di akses tanggal 10 Februari 2020.

Gjerde, M. (2016) Form follows Food: An Examination of Architecture's Role in Urban Farming. PP.249-258. New Zealand: Victoria University of Wellington

Handayani, I. (2017). 11 Persen Masyarakat Indonesia Rutin Makan di Luar Rumah dalam https://www.beritasatu.com/gaya-hidup/432721-11-persen-masyarakatindonesia-rutin-makan-di-luar-rumah di akses tanggal 13 Februari 2020

Herimsath, C. (1988). Behavioral Architecture. US: McGraw-Hill.

McLaren, D; Agyeman, J. (2015). Sharing Cities: A Case for Truly Smart and Sustainable Cities. US: MIT Press

Mowen, C. J. dan Minor, M. (2002). Perilaku Konsumen. Jakarta: Erlangga

Nordisk, N. (2015). Cities Changing Diabetes. US: NN

Oldenburgh, R. (1989). The Great Good Place. US: Da Capo Press

Rapp, M. A. (2017). Cities and Mental Health. dalam jurnal Deutsches Arzteblatt International,

114(8): 121-127. Berlin: Department of Epidemiology and Healthy Monitoring of the Robert Koch Institure

Tschumi, B. (2005). Event-Cities 3 Concept vs. Context vs. Content. US: MIT Press

Tuan, Y.F. (1977). Space and Place: The Perspective of Experience. US: University of Minnesota Press 